Illinois State University

ISU ReD: Research and eData

Theses and Dissertations

$3-8-2021$

\title{
Relationship Between Acute: Chronic Ratio And Injury In Women'S Collegiate Soccer Players
}

Jake A. Schwab

Illinois State University, schwab.jake86@gmail.com

Follow this and additional works at: https://ir.library.illinoisstate.edu/etd

Part of the Kinesiology Commons

\section{Recommended Citation}

Schwab, Jake A., "Relationship Between Acute: Chronic Ratio And Injury In Women'S Collegiate Soccer Players" (2021). Theses and Dissertations. 1412.

https://ir.library.illinoisstate.edu/etd/1412

This Thesis is brought to you for free and open access by ISU ReD: Research and eData. It has been accepted for inclusion in Theses and Dissertations by an authorized administrator of ISU ReD: Research and eData. For more information, please contact ISUReD@ilstu.edu. 


\section{RELATIONSHIP BETWEEN ACUTE: CHRONIC RATIO AND INJURY IN WOMEN'S COLLEGIATE SOCCER PLAYERS}

\section{JAKE A. SCHWAB}

\section{Pages}

Purpose: The goal of this study was to analyze the relationship between the acute:chronic training load ratio and incidence of injury within a women's collegiate soccer team over the course of their regular season. Methods: Thirty female collegiate soccer players wore Polar Team Pro heart rate monitors over the course of their season with eight sustaining injury. Two injuries were season ending, four injuries kept athletes out multiple weeks, and two injuries kept athletes out less than one week. Training load and distance were tracked for all individual practices, team practices, and games. Data was extracted from the Polar Team Pro website and exported into Microsoft Excel. Total training load and distance was calculated for the respective "current week" of the season and divided by the previous four weeks to calculate the acute:chronic training load ratio. For the current week, total training load and distance would be totaled for all athletes up to the day of injury. Injuries that occurred on Sunday were classified as last day of the week, while injuries that occurred any other day were classified as middle of the week. Averages of all healthy athletes' data were compared to the injured athlete's data every week injury was recorded, with higher differences found in the middle of the week versus the end of the week. Results: For injuries that occurred at the end of the week, the average acute:chronic ratio difference between healthy athletes and the injured athletes was $0.073 \pm 0.05$ units for the training load ratio and $0.069 \pm 0.03$ units for the distance ratio. These athletes 
averaged the 15th highest acute:chronic ratio for both acute:chronic ratios out of thirty total athletes. These differences increased for injuries that happened during the week, as the average difference for the training load ratio was $0.087 \pm 0.06$ units and $0.139 \pm 0.11$ units for the distance ratio. These athletes averaged the 11th highest acute:chronic ratio for both acute:chronic ratios out of thirty total athletes. Conclusion: Measuring the acute:chronic training load ratio the way it was done in this study was not helpful in minimizing injury risk. The rolling average method of measuring the acute:chronic ratio needs continued research with finding zones to best minimize injury for athletes.

KEYWORDS: Sports Science; Acute:Chronic Ratio; Training Load; Heart Rate; Injury; Soccer 
RELATIONSHIP BETWEEN ACUTE: CHRONIC RATIO AND INJURY IN WOMEN'S

COLLEGIATE SOCCER PLAYERS

JAKE A. SCHWAB

A Thesis Submitted in Partial

Fulfillment of the Requirements

for the Degree of

MASTER OF SCIENCE

School of Kinesiology and Recreation

ILLINOIS STATE UNIVERSITY

2021 
(C) 2021 Jake A. Schwab 
RELATIONSHIP BETWEEN ACUTE: CHRONIC RATIO AND INJURY IN WOMEN'S

COLLEGIATE SOCCER PLAYERS

JAKE A. SCHWAB

COMMITTEE MEMBERS:

Dale D. Brown, Chair

Kelly R. Laurson

Daniel J. Dodd 


\section{ACKNOWLEDGMENTS}

I would like to express my appreciation to my thesis chair, Dr. Dale Brown, who is the reason I have made it as far as I have. This study would not have happened without his continuous support and help. I would also like to thank my committee members Dr. Dodd and Dr. Laurson for aiding as a part of this study when needed. To Brad Silvey and the entire Illinois State University Soccer Program, thank you for the opportunity to not only work with a phenomenal staff, but a phenomenal team. Lastly, I would like to thank Ryan Swenson and the rest of the strength and conditioning staff for allowing me to come into their home and start this project with them. I truly could not have asked for a better group of individuals to be a part of this with. 


\section{CONTENTS}

Page

ACKNOWLEDGMENTS

CONTENTS

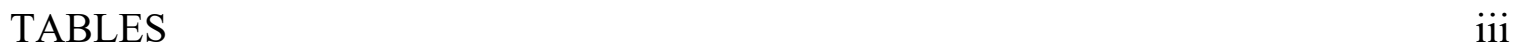

CHAPTER I. RELATIONSHIP BETWEEN ACUTE: CHRONIC RATIO AND

INJURY IN WOMEN'S COLLEGIATE SOCCER PLAYERS 1

$\begin{array}{ll}\text { Introduction } & 1\end{array}$

Methods 3

$\begin{array}{ll}\text { Participants } & 3\end{array}$

Sample and Injury $\quad 3$

Athlete Monitoring 3

Acute:Chronic Ratio $\quad 7$

$\begin{array}{ll}\text { Statistical Analysis } & 7\end{array}$

$\begin{array}{ll}\text { Results } & 8\end{array}$

$\begin{array}{ll}\text { Discussion } & 9\end{array}$

$\begin{array}{ll}\text { Tables } & 13\end{array}$

$\begin{array}{ll}\text { References } & 31\end{array}$

CHAPTER II. EXTENDED LITERATURE REVIEW 35

$\begin{array}{ll}\text { References } & 41\end{array}$

APPENDIX: CONSENT FORM 43 
Table

\section{TABLES}

1. Athlete comparisons for injury to healthy for training load and distance acute:chronic ratios

2. Acute:chronic ratios for training load for all athletes for injury 1

3. Acute:chronic ratios for distance for all athletes for injury 1

4. Acute:chronic ratios for training load for all athletes for injury 2

5. Acute:chronic ratios for distance for all athletes for injury 2

6. Acute:chronic ratios for training load for all athletes for injury 3

7. Acute:chronic ratios for distance for all athletes for injury 3

8. Acute:chronic ratios for training load for all athletes for injury 4

9. Acute:chronic ratios for distance for all athletes for injury 4

10. Acute:chronic ratios for training load for all athletes for injury 5

11. Acute:chronic ratios for distance for all athletes for injury 5

12. Acute:chronic ratios for training load for all athletes for injury 6

13. Acute:chronic ratios for distance for all athletes for injury 6

14. Acute:chronic ratios for training load for all athletes for injury 7

15. Acute:chronic ratios for distance for all athletes for injury 7

16. Acute:chronic ratios for training load for all athletes for injury 8

18. Team average training loads, distances, acute:chronic training load ratios, and acute:chronic distance ratios averaged for each week of the regular season 


\section{CHAPTER I: RELATIONSHIP BETWEEN ACUTE: CHRONIC RATIO AND INJURY IN WOMEN'S COLLEGIATE SOCCER PLAYERS}

\section{Introduction}

Monitoring the training loads and distances in elite athletes during practice and competition has become very popular in the sports science world over recent years (1). These training loads are characterized as either internal or external. Internal training load is defined as the relative physiological stressors placed on athletes during training or competition, and this can be measured by heart rate response, blood lactate, or oxygen consumption (1-5). External training load is any work that is performed by the athlete during training and competition, and this can be measured as power output, speed, acceleration, and total distance covered using global positioning systems (GPS) devices (1-5). The latter option is the most common tool used to measure external training load, and some of these devices can measure both the external and internal training load (1). Heart rate monitoring systems with GPS, including the Polar Team Pro system, is one of the devices that can measure both.

Internal and external training load have also been used to create something termed the acute:chronic ratio (2-4,6-12). The acute:chronic ratio is an athlete's current week of training load divided by the average athlete's weekly total training load over the four weeks prior $(2-4,6-$ 10). There has also been some research that look at the two weeks or three weeks prior to the current week when calculating the acute:chronic ratio (4). This ratio has been used for internal training load data, as well as external training load data. The goal of this ratio being created was to measure how an athlete's workload changes from week to week and determine the rate of change of it. Research has shown that some relationship exists between this ratio and variables of athlete performance, including their susceptibility to injury $(3,4)$ 
Injuries have been shown to negatively influence overall performance in sports leagues around the world, including the Union of European Football Association $(13,14)$. When teams had a low injury burden and a high match availability, they had a higher final league ranking. These measures were also associated with an increase in points per league match, as well as in increase in the Union of European Football Association Season Club coefficient, which reflected success in their champions league (13). Another study looked at injuries and how they impair the chance of successful performance, which again showed that an increased availability of teammates decreased the risk failure (15). Pre-season and in-season injuries were then associated with a high risk of failure in that sport. Injury has a detrimental effect on overall athlete performance, and the acute:chronic ratio is one of the newest tools to attempt to prevent this.

The acute:chronic ratio has been looked at by multiple studies in an attempt to prevent and predict injury. Multiple studies have found a specific range of the acute:chronic ratio in which the athlete is least susceptible to injury for both internal and external training load, with the range being $0.8-1.3(2,7)$. It has also been shown that having a high chronic workload while staying in these ranges can minimize it even more $(5,16-18)$. In other cases, though, an association has been seen between the ratio and injury, but it is a poor tool to use to predict injury (4).

The goal of this study was to examine the association between the acute:chronic ratio and injury in division I female collegiate soccer athletes. Both internal and external training load were looked at using the Polar Team Pro system. 


\section{Methods}

\section{Participants}

Data was collected from a Division I Collegiate Women's Soccer Team $(n=30)$. Mean age, height, and body weight were $20.0 \pm 1.2$ years, $65.1 \pm 2.1 \mathrm{in}$, and $136.5 \pm 13.8 \mathrm{lbs}$., respectively. Within the subject group, positions compromised of 3 forwards, 14 midfielders, 10 defenders, and 3 goalkeepers. Players participated in team practices, conditioning sessions, and competed in games within the Division 1 National Collegiate Athletics Association (NCAA) during the 2019 regular season. All data was obtained from the team's database, but without any identifying player information. Ethical approval was obtained from the Human Research Ethics Committee of Illinois State University.

\section{Sample and Injury}

A total of 30 subjects were used as a part of this study. All 30 were college-aged female division I collegiate soccer athletes. Of the 30 total subjects, eight had sustained injury over the course of their regular season. Of the eight injuries, two of them were season ending, four kept the athletes out for multiple weeks, and the final two kept the athletes out for less than one week. Injuries were defined as anything that kept the athlete out of practice or games that was kept on record by the team's NATA certified athletic trainer. The athletic trainer followed medical procedures of the medical staff when injury did occur. Extent and timeline to return from the injury were determined by the athletic trainer with the medical staff. The same athletic trainer worked with the team the entire season and attended all games and practices.

\section{Athlete Monitoring}

Athletes were monitored via GPS monitoring devices. This was done through the Polar Team Pro system, in which all athletes wore a chest-based heart rate monitor that calculated their total training load points and total distance. Training load is calculated using an equation created 
by Polar that uses heart rate response, duration, VO2 max, age, sex, weight, aerobic threshold, and anaerobic threshold. Heart rate response and training time are the two largest factors used as a part of that equation, while anaerobic threshold, aerobic threshold, and VO2 max were all estimated based off the athlete's demographic information. Maximal heart rate was also measured through Yo-Yo conditioning tests for each individual athlete. GPS was used to measure the total distance the athlete covers, which is exported out of Polar as yards and converted to miles for this study. The athletes would wear these devices during all practices, games, and individual conditioning sessions. All data for all of these sessions were exported from Polar via Microsoft Excel to total weekly training load and weekly distance.

Archived participant data from the Polar Team Pro Heart Rate Monitoring System (Polar Team Pro Sensor; Polar Electro Inc., Bethpage, NY USA) was used as the primary data source for this research study. The Polar Team Pro Heart Rate Monitoring System consists of an iPad, base station, Polar heart rate monitor, and elastic chest strap.

The iPad is used for recording sessions when the team is wearing their Polar heart rate monitors, such as their practices, games, and conditioning sessions. The iPad is also the device that is needed to act as the host device for the Polar Team Pro application, which is used to collect, analyze, and store the data from the base station and Polar heart rate monitors.

The base station acts as the link between the data recorded from the Polar Team Pro heart rate monitors and the online software provided by Polar that the data is uploaded to. The base station acts as a wireless router, providing communication between the station and the online computer software for the heart monitor data to be uploaded to. The heart rate monitors are placed on this base station after every use to be charged, and to allow the data from the monitors to be uploaded. 
The Polar Team Pro heart rate monitor was worn by every athlete on an elastic strap. Within the heart monitor, there is an accelerometer, gyroscope, digital compass, and heart rate monitor collecting data. The heart rate monitors integrated GPS at $10 \mathrm{~Hz}$, a MEMS motion sensor at $200 \mathrm{~Hz}$, and the heart rate monitor that samples at $1 \mathrm{k} \mathrm{Hz}$. The heart rate monitor was placed on the elastic strap that was worn by the athlete. The athlete then placed the elastic strap with the heart rate monitor in place around the chest against the skin.

There are multiple variables that are recorded and analyzed using the software. These variables include the following: heart rate, intensity based on different heart rate zones, total distance in yards, max speed in MPH, average speed in MPH, number of sprints performed based on an acceleration threshold, distance in speed zones 1-5, training load score, recovery time, calories burned, and number of accelerations performed in 8 different zones. All of these variables are displayed when exporting data from the online software, with a majority of them being displayed live on the iPad during sessions. Only the investigator collecting the data can see the data, which required the informed consent form.

The equipment was used by the athlete's sport coaches and training staff during conditioning, practice, game situations. The data is then exported from the online Polar Team Pro software system and analyzed using Microsoft Excel.

Some variables are taken directly from Polar Electro Inc. (Polar Team Pro) software, whereas others are derived from a separate data analysis within Microsoft Excel. The Polar Team Pro derived data included the following:

- Distance (Miles): The total distance covered through walking, jogging, running, and sprinting 
- Training Load (TL): Training Load is based on the intensity and duration of any session. The intensity of a session is measured using heart rate and duration, and the calculation is further affected by personal information such as age, sex, weight, VO2max, sport, aerobic threshold, and anaerobic threshold.

The data derived using information from the Polar Team Pro online software using Microsoft Excel includes the following:

- Acute (1-week) Internal Load: The accumulation of training load points in a week during conditioning, practices, and games.

- Acute (1-week) External Load: The accumulation of total distance covered (miles) in a week during conditioning, practices, and games.

- Chronic (4-week average) Internal Load: The average of training load points in a 4week block, including conditioning, practices, and games.

- Chronic (4-week average) External Load: The average of total distance covered (miles) in a 4-week block, including conditioning, practices, and games.

- Acute:Chronic Internal Training Load Ratio: Ratio dividing acute (1 week) internal training load by previous chronic training load (4-week average)

- Acute:Chronic External Training Load Ratio: Ratio dividing acute (1 week) external total distance covered (miles) load by previous chronic external total distance covered (4week average)

(All internal training load variables are measured in arbitrary units) 


\section{Acute:Chronic Ratio}

The acute:chronic ratio was measured on a weekly basis, with the standard week being Monday through Sunday. On the day an injury was reported for an athlete, the acute:chronic ratio would be calculated from Monday to that day of the week and divided by the previous four weeks instead of doing the entire week divided by the previous four weeks. For example, if an injury for an athlete was reported on a Wednesday, training load and distance would be totaled from Monday to Wednesday and divided by the previous four whole weeks. This way, comparisons can be seen by every athlete at the same time to see if the injured athlete had a higher or lower acute:chronic ratio than the rest of the athletes who stayed healthy that day. Injuries listed as "Middle of Week" occurred Monday through Saturday, while injuries listed as "End of Week" occurred on Sunday.

\section{Statistical Analysis}

Once games, practices, and games were completed, the Polar Team Pro sensors were plugged into their docking station. As soon as they were docked, data from the sensors were uploaded to the Polar Team Pro web server. This data from the Polar Team Pro server was exported into Microsoft Excel where pivot tables and pivot charts were created to analyze the data. These charts and pivot tables were used to convert distance from yards to miles, total weekly distance and training load points, find the average total weekly training load points and distance from the previous four weeks, and divide the current week's total training load points and distance by the average totals from the previous four weeks for each of those values. Average acute:chronic ratios were found for all athletes for each week an injury occurred and the difference between this average and the injured athlete's data was measured. Averages were then found for all of the healthy athlete acute:chronic ratios, injured athlete acute:chronic ratios, and 
all of the difference. Injuries were organized by those that happened during the week, and those that happened at the end of the week. All athlete weekly total training loads, distances, acute:chronic training load ratios, and acute:chronic distance ratios were averaged for each week of the season to display team averages over the course of the season.

\section{Results}

The average acute:chronic ratio for athletes injured during the week was $0.701 \pm 0.28$ units for training load, and $0.773 \pm 0.29$ units for distance. The average acute:chronic ratio for injuries that occurred at the end of the week was $0.933 \pm 0.15$ units for training load, and $1.01 \pm$ 0.18 units for distance. For injuries that occurred at the end of the week, the average acute:chronic ratio difference between healthy athletes and the injured athletes was $0.073 \pm 0.05$ units for the training load ratio and $0.069 \pm 0.03$ units for the distance ratio. For the athletes who were injured at the end of the week, they averaged the $15^{\text {th }}$ highest acute:chronic ratio for both total distance and training load out of thirty total athletes. These differences increased for injuries that happened during the week, as the average difference for the training load ratio was $0.087 \pm 0.06$ units and $0.139 \pm 0.11$ units for the distance ratio. For these athletes who were injured during the week, they averaged the $11^{\text {th }}$ highest acute:chronic ratio for both total distance and training load out of thirty total athletes. Table 1 shows the comparisons between the injured athlete each week with the average of all the healthy athletes. It shows the difference for each occurrence between the two groups, as well as all of the averages of all occurrences during the week and at the end of the week. Tables 2-17 show all of the ratios for each injury occurrence, with one table showing the ratio for training load and the other table showing the ratio for distance. The athlete and row were highlighted to signify the individual who was injured, and all 
are sorted from highest to lowest to show if the individual's ratios were higher, lower, or about the same as the rest of the team. Athletes with blank cells did not practice or compete that week.

\section{Discussion}

Acute:chronic ratios for both training load and distance varied greatly for both injuries that occurred during the week, as well as at the end of the week. When looking at the ratio for each occurrence of injury occurring at the end of the week, the injured athlete fell within healthy ranges every time. For injuries that occurred during the week, the injured athlete was either below or within healthy ranges, but still showed similar results as the rest of the team. The way the acute:chronic ratio was measured, especially for injuries that occurred in the middle of the week, was also not effective in predicting injury. The goal was to compare all athletes to each other whenever an injury occurred, but if these injuries occurred during the week, there was not a full seven days to use acutely to compare with the four weeks prior. The acute:chronic ratio uses whole weeks to as a part of the calculations but for injuries that occurred during the week, this timeline could have been shortened to as small as two days, not using the acute:chronic ratio as intended. A study by Murray at al. looked at the acute:chronic ratio for running workloads of Australian football players (19). Distance was mainly looked at, but ratios of 2.0 and greater were the main numbers found to greatly increase the likelihood to sustain injury, which is much higher than previously researched healthy ranges. Studies have shown to see an association between injury occurrence and severity with different acute:chronic ratios, but they did not prove or support the existence of a specific healthy range that diminishes injury risk (20).

Studies have looked more at the exponentially weighted averages more instead of using rolling averages, as using rolling averages have come in to question when trying to detect injury chronically (21). This newer calculation has proven to be more sensitive in detecting injury, and 
it is different when compared to rolling averages because it weighs the more recent weeks more than the older weeks when calculating the acute:chronic ratio. Research has shown that rolling averages and exponentially weighted moving averages are both associated with injury risk, but the exponentially weighted moving average is more sensitive to detect those injury risks (22). This exponentially weighted moving average has also been used during a full NCAA football season, where individuals with a low 21 day chronic workload were found to have a higher risk of being injured with spikes in the acute workload (23). Even simple methods like looking at daily measured RPE versus looking at the acute:chronic ratio over time has shown to be better at looking at the recovery stress-state of an athlete, which in turn could lead to injury (24). The acute:chronic ratio is used most for finding connections to injury, but all workloads are shown to effect injury, acutely and chronically. (25).

Other methods used to find a connection with injury have been found acutely instead of chronically and could prove to be better methods for establishing associations to injury. One example of this is looking at three-day workloads by themselves instead of comparing those workloads to weeks prior to it. Having a high three-day workload is significantly associated with an increased risk of injury, while the acute:chronic ratio used with this had no clear relationship with injury (26). Spikes in the acute workload itself also shows to have an association with increases in injury risk. However, these spikes are still related to the chronic workload where if acute workloads compared to the chronic workloads were negative or less than the chronic workload, the risk of injury increased. This was the same if the acute workload was greater than the chronic workload by $200 \%$ (27). With all the different ways and methods to find associations with injury, there has been no definitive answer for other options for healthy ranges, as well as what is considered high acute workloads and high chronic workloads. 
Most research has either looked at the general consensus healthy ranges when looking at the acute:chronic ratio or has rarely looked at the acute and chronic workloads separately. Another ratio that has been found to be considered high risk for an athlete to practice and compete at was greater than 1.5 and lower than 0.6 , which are both off when compared to healthy ranges of $0.8-1.3$ (28). There is also no improvement in the ability to identify these highrisk conditions by altering the acute or chronic time periods. When looking at loads acutely and chronically by themselves instead of together, there is no true definition of what is considered high or low. High loads in either category can also have variable effects on athletes, being positive or negative. The rate at which the load changes is proving to be more important, as changes in weekly load should be less than $10 \%$ to ensure the athlete stays in positive adaptation and reduce the risk of injuries. Again, there are no specific numbers for training load to define what is high or low in both categories (29).

The main limitation of this study is how the acute:chronic ratio was measured, especially for injuries that occurred during the week. A full week was not used acutely and still compared to four whole previous weeks, which is not the goal of the acute:chronic ratio. Other limitations include the unknown of what the athlete does outside of practice and competition, which would possibly increase those workloads and changing those ratios. The GPS monitoring devices were also not worn during any type of strength or weightlifting sessions, which can increase those workloads as well. The acute:chronic ratio also does not take contact injuries or other sources of injury into account when using it, showing how injury could still occur when all loads are normal for the athlete.

Overall, the method used to measure the acute:chronic ratio in this study was not helpful with predicting injury. All injuries fell within ranges considered healthy from previous studies, also showing that current zones considered healthy may not be good zones to use. The rolling 
average method of measuring the acute:chronic ratio should be combined with other methods to predict injury, such as the exponentially weighted moving average method of measuring the acute:chronic ratio. These methods should continue to be studied and modified to develop a more precise portrayal of this relationship with more consistent findings. 


\section{Tables}

Table 1. Athlete comparisons for injury to healthy for training load and distance acute:chronic ratios

\begin{tabular}{|c|c|c|c|c|c|c|}
\hline \multicolumn{7}{|c|}{ Last Day of Week } \\
\hline & \multicolumn{2}{|c|}{$\begin{array}{c}\text { Injured Athlete } \\
\text { Data }\end{array}$} & \multicolumn{2}{|c|}{$\begin{array}{l}\text { Avg. Healthy } \\
\text { Athlete Data }\end{array}$} & \multicolumn{2}{|c|}{ Differences } \\
\hline Occurrence & $A: C T L$ & A:C DIS & $A: C T L$ & A:C DIS & $A: C T L$ & A:C DIS \\
\hline Injury 1 & 1.10 & 1.22 & 1.08 & 1.16 & 0.024 & 0.067 \\
\hline Injury 2 & 0.853 & 0.887 & 0.923 & 0.923 & 0.070 & 0.035 \\
\hline Injury 3 & 0.844 & 0.924 & 0.970 & 1.03 & 0.126 & 0.104 \\
\hline AVERAGES & 0.933 & 1.01 & 0.990 & 1.04 & 0.073 & 0.069 \\
\hline \multicolumn{7}{|c|}{ Middle of Week } \\
\hline & \multicolumn{2}{|c|}{$\begin{array}{c}\text { Injured Athlete } \\
\text { Data }\end{array}$} & \multicolumn{2}{|c|}{$\begin{array}{r}\text { Avg. Healthy } \\
\text { Athlete Data }\end{array}$} & \multicolumn{2}{|c|}{ Differences } \\
\hline Occurrence & $A: C T L$ & A:C DIS & $A: C T L$ & A:C DIS & $A: C T L$ & A:C DIS \\
\hline Injury 4 & 0.538 & 0.678 & 0.522 & 0.595 & 0.015 & 0.084 \\
\hline Injury 5 & 0.335 & 0.340 & 0.190 & 0.216 & 0.145 & 0.124 \\
\hline Injury 6 & 0.819 & 1.07 & 0.697 & 0.764 & 0.122 & 0.303 \\
\hline Injury 7 & 0.746 & 0.761 & 0.783 & 0.768 & 0.036 & 0.007 \\
\hline Injury 8 & 1.07 & 1.02 & 1.18 & 1.20 & 0.115 & 0.180 \\
\hline AVERAGES & 0.701 & 0.773 & 0.675 & 0.708 & 0.087 & 0.139 \\
\hline
\end{tabular}

*A:C TL: Acute:Chronic Training Load Ratio

*A:C DIS: Acute:Chronic Distance Ratio

*Last Day of Week: Injuries that Occurred on Sunday

*Middle of Week: Injuries that Occurred on any day Except Sunday 
Table 2. Acute:chronic ratios for training load for all athletes for injury 1

\begin{tabular}{|l|r|}
\hline Player ID & A:C TL \\
\hline CC & 3.794 \\
\hline F & 1.535 \\
\hline K & 1.393 \\
\hline O & 1.186 \\
\hline DD & 1.175 \\
\hline A & 1.101 \\
\hline L & 1.099 \\
\hline T & 1.080 \\
\hline AA & 1.077 \\
\hline W & 1.073 \\
\hline BB & 1.066 \\
\hline Q & 1.064 \\
\hline V & 1.011 \\
\hline C & 1.006 \\
\hline G & 1.003 \\
\hline U & 0.995 \\
\hline D & 0.988 \\
\hline M & 0.969 \\
\hline S & 0.958 \\
\hline E & 0.951 \\
\hline X & 0.950 \\
\hline S & 0.851 \\
\hline B & 0.849 \\
\hline N & 0.825 \\
\hline H & 0.813 \\
\hline P & 0.791 \\
\hline P & 0.766 \\
\hline Y & 0.716 \\
\hline J & 0.697 \\
\hline
\end{tabular}

*A:C TL: Acute:Chronic Training Load Ratio 
Table 3. Acute:chronic ratios for distance for all athletes for injury 1

\begin{tabular}{|l|r|}
\hline Player ID & A:C Distance \\
\hline CC & 3.027 \\
\hline BB & 1.502 \\
\hline K & 1.333 \\
\hline O & 1.322 \\
\hline T & 1.317 \\
\hline F & 1.308 \\
\hline W & 1.276 \\
\hline A & 1.223 \\
\hline DD & 1.213 \\
\hline B & 1.153 \\
\hline$H$ & 1.140 \\
\hline L & 1.124 \\
\hline E & 1.113 \\
\hline AA & 1.090 \\
\hline V & 1.081 \\
\hline Q & 1.053 \\
\hline C & 1.036 \\
\hline$M$ & 1.032 \\
\hline Y & 1.025 \\
\hline D & 1.016 \\
\hline U & 1.015 \\
\hline X & 1.007 \\
\hline P & 1.004 \\
\hline I & 0.983 \\
\hline G & 0.968 \\
\hline S & 0.942 \\
\hline N & 0.932 \\
\hline R & 0.904 \\
\hline$Z$ & 0.901 \\
\hline J & 0.708 \\
\hline & \\
\hline
\end{tabular}

*A:C Distance: Acute:Chronic Distance Ratio 
Table 4. Acute:chronic ratios for training load for all athletes for injury 2

\begin{tabular}{|l|r|}
\hline Player ID & A:C TL \\
\hline M & 1.169 \\
\hline W & 1.153 \\
\hline S & 1.147 \\
\hline U & 1.081 \\
\hline J & 1.054 \\
\hline C & 1.044 \\
\hline CC & 1.038 \\
\hline X & 1.013 \\
\hline I & 1.011 \\
\hline L & 1.009 \\
\hline A & 0.987 \\
\hline AA & 0.976 \\
\hline P & 0.970 \\
\hline T & 0.967 \\
\hline V & 0.947 \\
\hline BB & 0.910 \\
\hline F & 0.879 \\
\hline DD & 0.868 \\
\hline Q & 0.853 \\
\hline Y & 0.818 \\
\hline G & 0.814 \\
\hline E & 0.813 \\
\hline R & 0.811 \\
\hline B & 0.802 \\
\hline H & 0.798 \\
\hline O & 0.780 \\
\hline N & 0.774 \\
\hline L & 0.772 \\
\hline K & 0.735 \\
\hline D & 0.638 \\
\hline
\end{tabular}

*A:C TL: Acute:Chronic Training Load Ratio 
Table 5. Acute:chronic ratios for distance for all athletes for injury 2

\begin{tabular}{|l|r|}
\hline Player ID & A:C Distance \\
\hline W & 1.186 \\
\hline U & 1.161 \\
\hline S & 1.138 \\
\hline AA & 1.029 \\
\hline A & 1.012 \\
\hline M & 1.004 \\
\hline C & 1.003 \\
\hline I & 0.976 \\
\hline V & 0.966 \\
\hline T & 0.959 \\
\hline P & 0.943 \\
\hline L & 0.934 \\
\hline J & 0.932 \\
\hline Y & 0.919 \\
\hline S & 0.914 \\
\hline CC & 0.902 \\
\hline DD & 0.899 \\
\hline X & 0.891 \\
\hline Q & 0.887 \\
\hline$H$ & 0.886 \\
\hline E & 0.862 \\
\hline F & 0.860 \\
\hline K & 0.858 \\
\hline O & 0.843 \\
\hline D & 0.832 \\
\hline R & 0.824 \\
\hline B & 0.812 \\
\hline G & 0.786 \\
\hline N & 0.765 \\
\hline BB & 0.663 \\
\hline
\end{tabular}

*A:C Distance: Acute:Chronic Distance Ratio 
Table 6. Acute:chronic ratios for training load for all athletes for injury 3

\begin{tabular}{|l|r|}
\hline Player ID & 1.377 \\
\hline BB & 1.316 \\
\hline Y & 1.283 \\
\hline CC & 1.259 \\
\hline P & 1.206 \\
\hline W & 1.202 \\
\hline H & 1.146 \\
\hline F & 1.122 \\
\hline N & 1.098 \\
\hline A & 1.073 \\
\hline I & 0.983 \\
\hline U & 0.969 \\
\hline DD & 0.967 \\
\hline B & 0.966 \\
\hline X & 0.937 \\
\hline O & 0.878 \\
\hline J & 0.878 \\
\hline E & 0.864 \\
\hline V & 0.859 \\
\hline AA & 0.844 \\
\hline C & 0.831 \\
\hline S & 0.830 \\
\hline D & 0.814 \\
\hline G & 0.807 \\
\hline L & 0.764 \\
\hline Z & 0.718 \\
\hline T & 0.716 \\
\hline K & 0.696 \\
\hline M & 0.601 \\
\hline R & \\
\hline Q & \\
\hline & \\
\hline & \\
\hline
\end{tabular}

*A:C TL: Acute:Chronic Training Load Ratio 
Table 7. Acute:chronic ratios for distance for all athletes for injury 3

\begin{tabular}{|l|r|}
\hline Player ID & A:C Distance \\
\hline BB & 1.367 \\
\hline CC & 1.284 \\
\hline P & 1.263 \\
\hline U & 1.261 \\
\hline Y & 1.240 \\
\hline D & 1.236 \\
\hline I & 1.226 \\
\hline H & 1.220 \\
\hline A & 1.137 \\
\hline W & 1.110 \\
\hline F & 1.076 \\
\hline N & 1.029 \\
\hline G & 1.021 \\
\hline DD & 1.018 \\
\hline B & 1.008 \\
\hline AA & 0.949 \\
\hline T & 0.931 \\
\hline C & 0.924 \\
\hline V & 0.910 \\
\hline J & 0.905 \\
\hline O & 0.902 \\
\hline R & 0.876 \\
\hline Z & 0.875 \\
\hline E & 0.873 \\
\hline L & 0.873 \\
\hline X & 0.870 \\
\hline S & 0.819 \\
\hline K & 0.766 \\
\hline M & 0.748 \\
\hline Q & \\
\hline & \\
\hline & \\
\hline
\end{tabular}

*A:C Distance: Acute:Chronic Distance Ratio 
Table 8. Acute:chronic ratios for training load for all athletes for injury 4

\begin{tabular}{|l|r|}
\hline \multicolumn{2}{|l|}{ Player ID A:C TL } \\
\hline J & 1.041 \\
\hline CC & 0.993 \\
\hline K & 0.776 \\
\hline AA & 0.614 \\
\hline S & 0.609 \\
\hline F & 0.591 \\
\hline X & 0.575 \\
\hline BB & 0.569 \\
\hline L & 0.550 \\
\hline C & 0.549 \\
\hline Y & 0.538 \\
\hline DD & 0.538 \\
\hline G & 0.515 \\
\hline T & 0.507 \\
\hline N & 0.507 \\
\hline O & 0.504 \\
\hline B & 0.478 \\
\hline P & 0.477 \\
\hline R & 0.474 \\
\hline H & 0.472 \\
\hline V & 0.471 \\
\hline M & 0.452 \\
\hline W & 0.424 \\
\hline U & 0.413 \\
\hline Q & 0.407 \\
\hline N & 0.380 \\
\hline D & 0.380 \\
\hline L & 0.377 \\
\hline E & 0.323 \\
\hline A & 0.178 \\
\hline
\end{tabular}

*A:C TL: Acute:Chronic Training Load Ratio 
Table 9. Acute:chronic ratios for distance for all athletes for injury 4

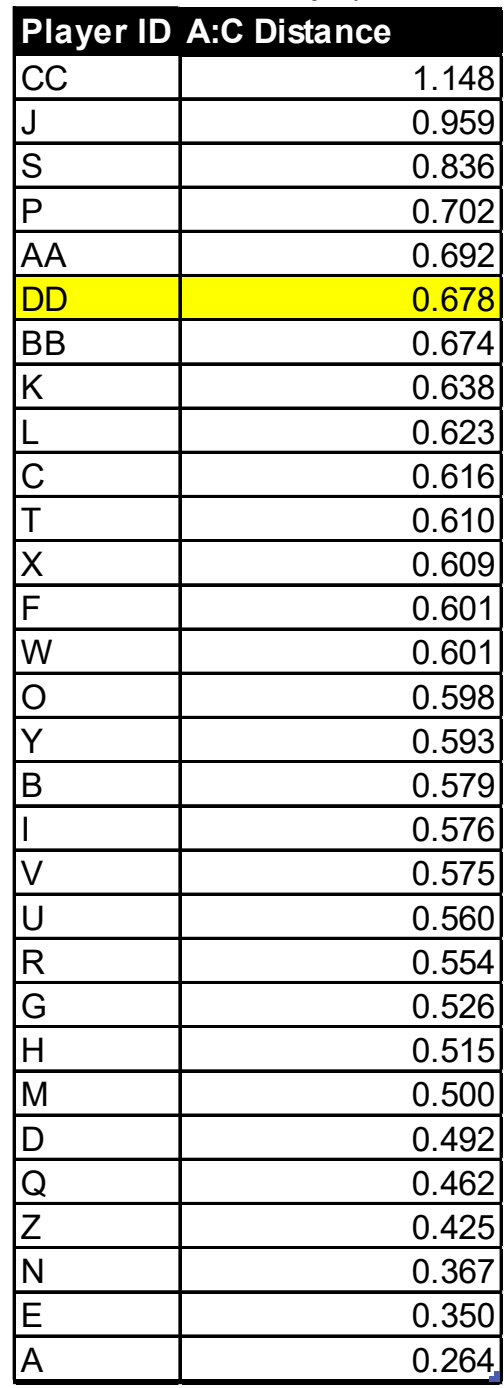

*A:C Distance: Acute:Chronic Distance Ratio 
Table 10. Acute:chronic ratios for training load for all athletes for injury 5

\begin{tabular}{|l|r|}
\hline Player ID & 0.463 \\
\hline CC & 0.335 \\
\hline R & 0.318 \\
\hline P & 0.304 \\
\hline H & 0.278 \\
\hline I TL \\
\hline BB & 0.277 \\
\hline Y & 0.266 \\
\hline D & 0.245 \\
\hline W & 0.245 \\
\hline M & 0.237 \\
\hline X & 0.233 \\
\hline U & 0.227 \\
\hline S & 0.222 \\
\hline Z & 0.209 \\
\hline N & 0.179 \\
\hline G & 0.179 \\
\hline C & 0.169 \\
\hline AA & 0.150 \\
\hline DD & 0.127 \\
\hline A & 0.122 \\
\hline J & 0.116 \\
\hline E & 0.111 \\
\hline O & 0.111 \\
\hline K & 0.105 \\
\hline L & 0.101 \\
\hline V & 0.087 \\
\hline T & 0.085 \\
\hline F & 0.078 \\
\hline B & 0.073 \\
\hline Q & \\
\hline & \\
\hline & \\
\hline
\end{tabular}

*A:C TL: Acute:Chronic Training Load Ratio 
Table 11. Acute:chronic ratios for distance for all athletes for injury 5

\begin{tabular}{|l|r|}
\hline Player ID & A:C Distance \\
\hline CC & 0.450 \\
\hline BB & 0.366 \\
\hline P & 0.350 \\
\hline D & 0.342 \\
\hline R & 0.340 \\
\hline H & 0.327 \\
\hline I & 0.322 \\
\hline U & 0.300 \\
\hline G & 0.271 \\
\hline W & 0.263 \\
\hline Z & 0.258 \\
\hline Y & 0.252 \\
\hline M & 0.235 \\
\hline X & 0.229 \\
\hline C & 0.222 \\
\hline S & 0.191 \\
\hline B & 0.163 \\
\hline AA & 0.156 \\
\hline A & 0.151 \\
\hline N & 0.143 \\
\hline DD & 0.142 \\
\hline V & 0.128 \\
\hline K & 0.122 \\
\hline O & 0.117 \\
\hline L & 0.116 \\
\hline J & 0.116 \\
\hline F & 0.109 \\
\hline E & 0.106 \\
\hline T & 0.100 \\
\hline Q & \\
\hline & \\
\hline$c$ & \\
\hline
\end{tabular}

*A:C Distance: Acute:Chronic Distance Ratio 
Table 12. Acute:chronic ratios for training load for all athletes for injury 6

\begin{tabular}{|l|r|}
\hline Player ID & 1.152 \\
\hline BB & 1.074 \\
\hline P & 1.034 \\
\hline Y & 1.026 \\
\hline CC & 0.986 \\
\hline H & 0.885 \\
\hline I & 0.819 \\
\hline U & 0.816 \\
\hline N & 0.813 \\
\hline W & 0.741 \\
\hline X & 0.729 \\
\hline F & 0.673 \\
\hline A & 0.658 \\
\hline DD & 0.650 \\
\hline G & 0.645 \\
\hline D & 0.642 \\
\hline S & 0.612 \\
\hline AA & 0.608 \\
\hline M & 0.601 \\
\hline C & 0.595 \\
\hline E & 0.584 \\
\hline J & 0.568 \\
\hline O & 0.563 \\
\hline L & 0.546 \\
\hline B & 0.511 \\
\hline V & 0.483 \\
\hline T & 0.449 \\
\hline Z & 0.439 \\
\hline R & 0.430 \\
\hline K & \\
\hline Q & \\
\hline & \\
\hline & \\
\hline
\end{tabular}

*A:C TL: Acute:Chronic Training Load Ratio 
Table 13. Acute:chronic ratios for distance for all athletes for injury 6

\begin{tabular}{|l|r|}
\hline Player ID & A:C Distance \\
\hline BB & 1.131 \\
\hline U & 1.067 \\
\hline P & 1.066 \\
\hline CC & 1.042 \\
\hline I & 1.035 \\
\hline D & 1.027 \\
\hline H & 1.013 \\
\hline Y & 0.997 \\
\hline G & 0.849 \\
\hline W & 0.772 \\
\hline N & 0.760 \\
\hline A & 0.748 \\
\hline X & 0.721 \\
\hline F & 0.718 \\
\hline DD & 0.712 \\
\hline R & 0.702 \\
\hline AA & 0.698 \\
\hline C & 0.692 \\
\hline S & 0.682 \\
\hline B & 0.663 \\
\hline J & 0.650 \\
\hline M & 0.629 \\
\hline L & 0.624 \\
\hline V & 0.621 \\
\hline E & 0.619 \\
\hline T & 0.607 \\
\hline O & 0.590 \\
\hline Z & 0.522 \\
\hline K & 0.515 \\
\hline Q & \\
\hline & \\
\hline
\end{tabular}

*A:C Distance: Acute:Chronic Distance Ratio 
Table 14. Acute:chronic ratios for training load for all athletes for injury 7

\begin{tabular}{|l|r|}
\hline Player ID & 1.245 \\
\hline CC & 1.229 \\
\hline R & 1.003 \\
\hline P & 0.937 \\
\hline S & 0.937 \\
\hline Y TL \\
\hline M & 0.901 \\
\hline BB & 0.870 \\
\hline N & 0.868 \\
\hline K & 0.846 \\
\hline AA & 0.829 \\
\hline H & 0.829 \\
\hline DD & 0.822 \\
\hline X & 0.818 \\
\hline E & 0.810 \\
\hline I & 0.770 \\
\hline L & 0.746 \\
\hline G & 0.734 \\
\hline O & 0.724 \\
\hline Z & 0.713 \\
\hline V & 0.689 \\
\hline A & 0.671 \\
\hline D & 0.631 \\
\hline W & 0.628 \\
\hline T & 0.618 \\
\hline J & 0.592 \\
\hline F & 0.516 \\
\hline U & 0.477 \\
\hline B & 0.423 \\
\hline C & \\
\hline Q & \\
\hline & \\
\hline & \\
\hline
\end{tabular}

*A:C TL: Acute:Chronic Training Load Ratio 
Table 15. Acute:chronic ratios for distance for all athletes for injury 7

\begin{tabular}{|l|r|}
\hline Player ID & A:C Distance \\
\hline CC & 1.100 \\
\hline X & 1.030 \\
\hline S & 0.959 \\
\hline R & 0.929 \\
\hline P & 0.868 \\
\hline N & 0.860 \\
\hline DD & 0.851 \\
\hline Z & 0.840 \\
\hline BB & 0.831 \\
\hline H & 0.807 \\
\hline E & 0.790 \\
\hline D & 0.787 \\
\hline A & 0.785 \\
\hline G & 0.785 \\
\hline M & 0.781 \\
\hline O & 0.778 \\
\hline AA & 0.774 \\
\hline L & 0.761 \\
\hline I & 0.736 \\
\hline W & 0.714 \\
\hline Y & 0.703 \\
\hline F & 0.667 \\
\hline K & 0.657 \\
\hline T & 0.630 \\
\hline V & 0.618 \\
\hline J & 0.614 \\
\hline B & 0.549 \\
\hline U & 0.289 \\
\hline C & \\
\hline Q & \\
\hline & \\
\hline
\end{tabular}

*A:C Distance: Acute:Chronic Distance Ratio 
Table 16. Acute:chronic ratios for training load for all athletes for injury 8

\begin{tabular}{|c|c|}
\hline Player ID & $A: C$ TL \\
\hline Z & 1.680 \\
\hline $\mathrm{L}$ & 1.434 \\
\hline $\bar{K}$ & 1.383 \\
\hline $\mathrm{R}$ & 1.347 \\
\hline $\mathrm{J}$ & 1.346 \\
\hline$A$ & 1.336 \\
\hline M & 1.322 \\
\hline W & 1.308 \\
\hline$D$ & 1.297 \\
\hline V & 1.250 \\
\hline $\mathrm{AA}$ & 1.242 \\
\hline $\mathrm{F}$ & 1.226 \\
\hline DD & 1.219 \\
\hline $\mathrm{E}$ & 1.183 \\
\hline $\mathrm{N}$ & 1.162 \\
\hline $\mathrm{O}$ & 1.153 \\
\hline CC & 1.087 \\
\hline $\mathrm{H}$ & 1.077 \\
\hline Y & 1.076 \\
\hline$B$ & 1.067 \\
\hline BB & 1.037 \\
\hline $\mathrm{G}$ & 1.018 \\
\hline $\mathrm{I}$ & 1.002 \\
\hline $\mathrm{P}$ & 0.992 \\
\hline$U$ & 0.989 \\
\hline$S$ & 0.963 \\
\hline $\mathrm{T}$ & 0.940 \\
\hline$x$ & 0.860 \\
\hline $\mathrm{C}$ & \\
\hline $\mathrm{Q}$ & \\
\hline
\end{tabular}

*A:C TL: Acute:Chronic Training Load Ratio 
Table 17. Acute:chronic ratios for distance for all athletes for injury 8

\begin{tabular}{|l|r|}
\hline Player ID & A:C Distance \\
\hline M & 1.652 \\
\hline Z & 1.507 \\
\hline J & 1.389 \\
\hline N & 1.384 \\
\hline K & 1.343 \\
\hline W & 1.336 \\
\hline V & 1.331 \\
\hline R & 1.313 \\
\hline E & 1.307 \\
\hline A & 1.296 \\
\hline L & 1.273 \\
\hline Y & 1.264 \\
\hline F & 1.235 \\
\hline AA & 1.224 \\
\hline DD & 1.223 \\
\hline T & 1.186 \\
\hline D & 1.131 \\
\hline BB & 1.121 \\
\hline CC & 1.082 \\
\hline O & 1.071 \\
\hline G & 1.027 \\
\hline S & 1.026 \\
\hline B & 1.017 \\
\hline H & 0.984 \\
\hline I & 0.976 \\
\hline P & 0.926 \\
\hline X & 0.875 \\
\hline U & 0.830 \\
\hline C & \\
\hline Q & \\
\hline & \\
\hline$c$ & \\
\hline
\end{tabular}

*A:C Distance: Acute:Chronic Distance Ratio 
Table 18: Team average training loads, distances, acute:chronic training load ratios, and acute:chronic distance ratios averaged for each week of the regular season

\begin{tabular}{|l|r|r|}
\hline \multicolumn{1}{|c}{$\begin{array}{r}\text { Team Average Weekly Total } \\
\text { Training Load }\end{array}$} & $\begin{array}{r}\text { Team Average of Weekly } \\
\text { Total Distance (Miles) }\end{array}$ \\
\hline Week 1 & 947.367 & 17.869 \\
\hline Week 2 & 864.100 & 17.040 \\
\hline Week 3 & 869.633 & 17.270 \\
\hline Week 4 & 793.800 & 15.249 \\
\hline Week 5 & 826.862 & 17.053 \\
\hline Week 6 & 612.481 & 12.330 \\
\hline Week 7 & 870.107 & 17.397 \\
\hline Week 8 & 581.536 & 12.482 \\
\hline Week 9 & 841.000 & 17.512 \\
\hline Week 10 & 566.643 & 11.443 \\
\hline Week 11 & 569.857 & 10.421 \\
\hline Week 12 & 834.643 & 15.266 \\
\hline & & \\
Weeks of the Season & Team Average of Acute:Chronic & Team Average of \\
\hline Week 1 & Training Load Ratio & Acute:Chronic Distance Ratio \\
\hline Week 2 & 1.078 & 1.158 \\
\hline Week 3 & 0.942 & 1.051 \\
\hline Week 4 & 0.958 & 1.038 \\
\hline Week 5 & 0.921 & 0.922 \\
\hline Week 6 & 0.966 & 1.025 \\
\hline Week 7 & 0.745 & 0.745 \\
\hline Week 8 & 1.134 & 1.126 \\
\hline Week 9 & 0.755 & 0.799 \\
\hline Week 10 & 1.190 & 1.200 \\
\hline Week 11 & 0.796 & 0.787 \\
\hline Week 12 & 0.799 & 0.712 \\
\hline
\end{tabular}




\section{REFERENCES}

1. Bourdon PC, Cardinale M, Murray A, Gastin P, Kellmann M, Varley MC, et al. Monitoring Athlete Training Loads: Consensus Statement. International Journal of Sports Physiology and Performance. 2017 Apr;12(s2):S2-161-S2-170.

2. Hulin BT, Gabbett TJ, Caputi P, Lawson DW, Sampson JA. Low chronic workload and the acute:chronic workload ratio are more predictive of injury than between-match recovery time: a two-season prospective cohort study in elite rugby league players. Br J Sports Med. 2016 Aug;50(16):1008-12.

3. Blanch P, Gabbett TJ. Has the athlete trained enough to return to play safely? The acute:chronic workload ratio permits clinicians to quantify a player's risk of subsequent injury. Br J Sports Med. 2016 Apr;50(8):471-5.

4. Fanchini M, Rampinini E, Riggio M, Coutts AJ, Pecci C, McCall A. Despite association, the acute:chronic work load ratio does not predict non-contact injury in elite footballers. Science and Medicine in Football. 2018 Apr 3;2(2):108-14.

5. Hulin BT, Gabbett TJ, Pickworth NJ, Johnston RD, Jenkins DG. Relationships Among PlayerLoad, High-Intensity Intermittent Running Ability, and Injury Risk in Professional Rugby League Players. International Journal of Sports Physiology and Performance. 2020 Mar 1;15(3):423-9.

6. Carey DL, Blanch P, Ong K-L, Crossley KM, Crow J, Morris ME. Training loads and injury risk in Australian football-differing acute: chronic workload ratios influence match injury risk. Br J Sports Med. 2017 Aug;51(16):1215-20. 
7. Hulin BT, Gabbett TJ, Lawson DW, Caputi P, Sampson JA. The acute:chronic workload ratio predicts injury: high chronic workload may decrease injury risk in elite rugby league players. Br J Sports Med. 2016 Feb;50(4):231-6.

8. Myers NL, Aguilar KV, Mexicano G, Farnsworth JL, Knudson D, Kibler WB. The Acute: Chronic Workload Ratio Is Associated with Injury in Junior Tennis Players. Med Sci Sports Exerc. 2020 May;52(5):1196-200.

9. Bowen L, Gross AS, Gimpel M, Li F-X. Accumulated workloads and the acute:chronic workload ratio relate to injury risk in elite youth football players. Br J Sports Med. 2017 Mar;51(5):452-9.

10. Sampson JA, Murray A, Williams S, Sullivan A, Fullagar HHK. Subjective Wellness, Acute: Chronic Workloads, and Injury Risk in College Football. J Strength Cond Res. 2019 Dec;33(12):3367-73.

11. Gabbett TJ. The training - injury prevention paradox: should athletes be training smarter and harder? Br J Sports Med. 2016 Mar;50(5):273-80.

12. Jaspers A, Kuyvenhoven JP, Staes F, Frencken WGP, Helsen WF, Brink MS. Examination of the external and internal load indicators' association with overuse injuries in professional soccer players. J Sci Med Sport. 2018 Jun;21(6):579-85.

13. Eirale C, Tol JL, Farooq A, Smiley F, Chalabi H. Low injury rate strongly correlates with team success in Qatari professional football. Br J Sports Med. 2013 Aug;47(12):807-8.

14. Hägglund M, Waldén M, Magnusson H, Kristenson K, Bengtsson H, Ekstrand J. Injuries affect team performance negatively in professional football: an 11-year follow-up of the UEFA Champions League injury study. Br J Sports Med. 2013 Aug;47(12):738-42. 
15. Drew MK, Raysmith BP, Charlton PC. Injuries impair the chance of successful performance by sportspeople: a systematic review. Br J Sports Med. 2017 Aug;51(16):1209-14.

16. Foster C, Daines E, Hector L, Snyder AC, Welsh R. Athletic performance in relation to training load. Wis Med J. 1996 Jun;95(6):370-4.

17. Fox JL, Stanton R, Sargent C, Wintour S-A, Scanlan AT. The Association Between Training Load and Performance in Team Sports: A Systematic Review. Sports Med. 2018 Dec;48(12):2743-74.

18. Stewart AM, Hopkins WG. Seasonal training and performance of competitive swimmers. Journal of Sports Sciences. 2000 Jan;18(11):873-84.

19. Murray NB, Gabbett TJ, Townshend AD, Hulin BT, McLellan CP. Individual and combined effects of acute and chronic running loads on injury risk in elite Australian footballers. Scand J Med Sci Sports. 2017 Sep;27(9):990-8.

20. Sedeaud A, De Larochelambert Q, Moussa I, Brasse D, Berrou J-M, Duncombe S, et al. Does an Optimal Relationship Between Injury Risk and Workload Represented by the "Sweet Spot” Really Exist? An Example From Elite French Soccer Players and Pentathletes. Front Physiol. 2020;11:1034.

21. Menaspà $\mathrm{P}$. Are rolling averages a good way to assess training load for injury prevention? $\mathrm{Br}$ J Sports Med. 2017 Apr;51(7):618-9.

22. Murray NB, Gabbett TJ, Townshend AD, Blanch P. Calculating acute:chronic workload ratios using exponentially weighted moving averages provides a more sensitive indicator of injury likelihood than rolling averages. Br J Sports Med. 2017 May;51(9):749-54. 
23. Sampson JA, Murray A, Williams S, Halseth T, Hanisch J, Golden G, et al. Injury riskworkload associations in NCAA American college football. J Sci Med Sport. 2018 Dec;21(12):1215-20.

24. Collette R, Kellmann M, Ferrauti A, Meyer T, Pfeiffer M. Relation Between Training Load and Recovery-Stress State in High-Performance Swimming. Front Physiol. 2018;9:845.

25. Windt J, Gabbett TJ. How do training and competition workloads relate to injury? The workload-injury aetiology model. Br J Sports Med. 2017 Mar;51(5):428-35.

26. Ahmun R, McCaig S, Tallent J, Williams S, Gabbett T. Association of Daily Workload, Wellness, and Injury and Illness During Tours in International Cricketers. Int J Sports Physiol Perform. 2019 Mar 1;14(3):369-77.

27. Hulin BT, Gabbett TJ, Blanch P, Chapman P, Bailey D, Orchard JW. Spikes in acute workload are associated with increased injury risk in elite cricket fast bowlers. Br J Sports Med. 2014 Apr;48(8):708-12.

28. Stares J, Dawson B, Peeling P, Heasman J, Rogalski B, Drew M, et al. Identifying high risk loading conditions for in-season injury in elite Australian football players. J Sci Med Sport. 2018 Jan;21(1):46-51.

29. Soligard T, Schwellnus M, Alonso J-M, Bahr R, Clarsen B, Dijkstra HP, et al. How much is too much? (Part 1) International Olympic Committee consensus statement on load in sport and risk of injury. Br J Sports Med. 2016 Sep;50(17):1030-41. 


\section{CHAPTER II: EXTENDED LITERATURE REVIEW}

The use of wearable devices and technology in athletics has become a very heavily researched topic over recent years. More specifically, the use of wearable devices during team activities such as practices, games, and conditioning sessions. A very popular way that this has been done is through the use of global positioning systems (GPS) devices with heart rate monitors. These devices can be used to measure external training load, which can be something such as the total distance an athlete covers during a week. It can also be used to measure internal training load, which is measured based off the amount of time an athlete spends in different heart rate zones of varying intensities. Both of these variables can be used to measure what is called the acute:chronic workload ratio, which uses rolling averages to compare training loads completed over the previous week to the average training load of the previous four weeks. The acute:chronic ratio has especially become a very popular topic over recent years in an attempt to make sure an athlete's weekly training load does not increase or decrease too drastically. Research has shown that increasing or decreasing load too fast can result in injury for athletes. Research has also shown that the rolling average used to calculate it has come into question, due to the use of rolling averages since it does not weigh more recent weeks more than older weeks (1). Research has found evidence that supports the acute:chronic ratio, but research has also called the acute:chronic ratio into question when attempting to predict injury in athletes.

One study conducted by Hulin in 2016 found that the acute:chronic ratio did indeed predict injury for elite rugby league players. Hulin and his team collected data from 53 players over two rugby seasons in an attempt to predict injury based off of their acute:chronic external training load ratio. The external training load method used was total distance for one week divided by the average distance of the previous four weeks. Hulin found that a very high ratio of 
greater than 2.11 gave the athlete a $16.7 \%$ risk for injury. The highest injury risk found for athletes was $28.6 \%$, which occurred when the athlete had a very high chronic workload paired with a very high two week average acute:chronic workload ratio of more than 1.54 . Hulin also found that it was the ratio that determined all of this information, and that the acute and chronic workloads by themselves did not consistently predict injury risk. Hulin determined that when the chronic workload was high and the acute:chronic ratio was between 0.85 and 1.35 , the athlete was at the lowest risk of injury. It was when athletes' acute:chronic ratio increased over 1.5 when the injury risk began to increase (2). This was all done using rolling averages, which has come into question by other research but ended up predicting injury in this study. For this study, only external training load was looked at, whereas there have been other studies that have looked at the acute:chronic ratios for both internal and external training load.

A study conducted by Arne Jaspers looked at both external and internal load indicators to find a relationship with overuse injury in professional soccer players. The external training load was total distance covered, while the internal training load was calculated by multiplying the RPE given by an athlete after practice by the total duration of the practice. Acute:chronic ratios were calculated for both by dividing the most recent week by the average of the previous four weeks. For total distance covered, an acute:chronic ratio of $0.88-1.11$ showed to be the most beneficial for the athletes. For the RPE multiplied by duration, an acute:chronic ratio of 0.85 1.12 showed to be the most beneficial for athletes (3). Both acute:chronic ratios are very similar, but these numbers are much different when compared to the numbers found in the previous study by Hulin. This is an example of why measuring the acute:chronic ratio using the rolling average has come into question as research shows mixed results on what the best ranges for the acute:chronic ratio are to stay in to reduce risk of injury. Reducing injury continues to be a large 
goal for many researchers though, as injury has shown to have detrimental effects on a team's performance.

Injury prevention and predicting injury has been researched heavily due to the detrimental effects injury has on a team's success, hence why the acute:chronic ratio has been looked into so much. Cristiano Eirale and others decided to look at the relationships between injury and different success factors in Qatari professional football. 10 first-division clubs were followed over one season beginning in August 2008 and ending in April 2009. Three teams ended up being excluded for providing inconsistent data over that time period. Relationships that were found ended up being clubs with a lower injury incidence had a higher league position, more games won, more goals scored, a greater goal difference, and more total league points (4). All of these relationships could show the negative effects injury has on a team, but the acute:chronic workload ratio may not be the solution to predicting injury.

This is an example of research that has shown that the acute:chronic ratio does not predict injury. Maurizio Fanchini looked at the acute:chronic workload ratio with thirty-four Italian football players. The acute:chronic ratio looked at the most recent week versus the previous two weeks, three weeks, and four weeks, and used RPE times duration to measure training load. When doing so, an association was found between injury and the acute:chronic ratio the previous 2-, 3- and, 4-week ratios. But even though association was found, these markers where association were found have very poor predicative validity to specifically identify individual players who could incur an injury based off of these load markers or specific acute:chronic ratios (5). With questioning the current way the acute:chronic ratio is measured and how it has shown mixed results in research, there have been other variations of the acute:chronic ratio that have been developed to try to better predict injury. 
The newer method using the acute:chronic ratio to predict injury and calculate injury risk is using exponentially weighted moving averages instead of rolling averages. The difference between the two methods is that in the exponentially weighted method, more recent weeks used in the chronic calculation are weighted more than weeks that are older. All weeks are treated equally when using the rolling averages. A study that looks at both equations was done by Nicholas Murray on a group of 59 elite Australian football players. All athletes were from the same club, and the study lasted a total of two years. Total distance was the external training load that was looked at for this study, and relationships between injury and each acute:chronic ratio were found. Both models demonstrated significant associations between a very high acute:chronic ratio and an increased risk for injury for total distance, but the exponentially weighted method proved to be more sensitive at detecting these changes. The variance in injury explained by the acute:chronic ratio was significantly greater using the exponentially weighted method instead of using the rolling average method (6). This goes to show how using a different method of calculating the acute:chronic ratio can make that much more of a difference when comparing this method to the rolling average method. Measuring training load acutely by itself in certain situations has also proven to be a better option than using the rolling average method of the acute:chronic ratio.

Robert Ahmun and others decided to look at different time ranges for looking at training load and the acute:chronic ratio to measure it. Ahmun decided to look at 39 male international adolescent cricketers over a three-year period. Over this period, measures of wellness were recorded, training loads were calculated daily using the RPE times duration method, and injury and illness status was recorded daily. Acute and chronic workloads were calculated using threeday averages and fourteen-day averages instead of the usual seven day and four-week averages 
for the acute:chronic ratio. Each measure was modeled independently with injury. Ahmun found that a high three-day workload was significantly associated with an increased risk of injury, and this was the main variable Ahmun found associated with injury. There was no clear relationship found between injury and the acute:chronic ratio in this study. Short term high workloads and changes in an athlete's wellness status were associated with injury risk, but there was also significant individual variation between athletes (7). This is also not the only study that has shown a relationship between high acute workloads and injury.

Hulin analyzed 28 fast bowlers over the course of six years from cricket. The workload used for this study was the number of balls bowled per week for external workload rather than something such as total distance, and RPE times duration was used to calculate the internal training load. The previous week was used as the acute data, while the four weeks prior was all used as the chronic data. Rolling averages were used to calculate the chronic data and instead of calculating acute:chronic ratios, and acute:chronic ratios were calculated for both internal and external training load. Hulin found that when the acute internal workload training load grew greater than $200 \%$, the relative risk of injury increased drastically. This was also found for the external training load (8).

Overall, there are multiple methods researchers have investigated over the years in an attempt to predict injury. This has been done using technology and wearable devices in sports to accurately measure internal and external training load, which then in turn was used as a part of the acute:chronic ratio. The acute:chronic ratio gave mixed results, showing in some situations it proved significant, while in other situations not so much. In an attempt to avoid the negative effects of injury, the exponentially weighted method was created that had a more significant impact on detecting injury in sports when compared to the typical rolling average method. 
Looking at training load acutely even proved to be better in research than using the acute:chronic training load method with rolling averages. This is why research should be continued on all of these topics, because there is no concrete method that stands out when predicting injury for athletes. All of this shows results are still mixed for everything that has been done using the acute:chronic ratio, and also shows why continued research is needed. 


\section{REFERENCES}

1. Bourdon PC, Cardinale M, Murray A, Gastin P, Kellmann M, Varley MC, et al. Monitoring Athlete Training Loads: Consensus Statement. International Journal of Sports Physiology and Performance. 2017 Apr;12(s2):S2-161-S2-170.

2. Hulin BT, Gabbett TJ, Lawson DW, Caputi P, Sampson JA. The acute:chronic workload ratio predicts injury: high chronic workload may decrease injury risk in elite rugby league players. Br J Sports Med. 2016 Feb;50(4):231-6.

3. Jaspers A, Kuyvenhoven JP, Staes F, Frencken WGP, Helsen WF, Brink MS. Examination of the external and internal load indicators' association with overuse injuries in professional soccer players. Journal of Science and Medicine in Sport. 2018 Jun 1;21(6):579-85.

4. Eirale C, Tol JL, Farooq A, Smiley F, Chalabi H. Low injury rate strongly correlates with team success in Qatari professional football. Br J Sports Med. 2013 Aug;47(12):807-8.

5. Fanchini M, Rampinini E, Riggio M, Coutts AJ, Pecci C, McCall A. Despite association, the acute:chronic work load ratio does not predict non-contact injury in elite footballers. Science and Medicine in Football. 2018 Apr 3;2(2):108-14.

6. Murray NB, Gabbett TJ, Townshend AD, Blanch P. Calculating acute:chronic workload ratios using exponentially weighted moving averages provides a more sensitive indicator of injury likelihood than rolling averages. Br J Sports Med. 2017 May;51(9):749-54.

7. Ahmun R, McCaig S, Tallent J, Williams S, Gabbett T. Association of Daily Workload, Wellness, and Injury and Illness During Tours in International Cricketers. Int J Sports Physiol Perform. 2019 Mar 1;14(3):369-77. 
8. Hulin BT, Gabbett TJ, Blanch P, Chapman P, Bailey D, Orchard JW. Spikes in acute workload are associated with increased injury risk in elite cricket fast bowlers. Br J Sports Med. 2014 Apr;48(8):708-12. 


\section{APPENDIX: CONSENT FORM}

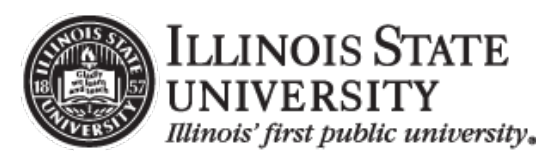

\section{Informed Consent to Participate in Research Physiological Analysis of Physical Performance Predictors in Sport and Activity Programs}

\section{Data Use for Research Purposes:}

You are invited to participate in a research study conducted by members of the School of Kinesiology and Recreation at Illinois State University, Normal, IL. The purpose of this study is to analyze the physical and physiological responses in collegiate athletes during training, conditioning, practices and games. The data to be used for this project will come from your archived/stored data that has been previously recorded within the Polar Team Pro System. Expectations for Your Involvement:

Participation in this study will not require you to do anything more than what you are already expected to do within the requirements of your sport program (conditioning, training, practice, games, etc.). By participating in this study, you are agreeing to allow the data collected as a part of sports program to be used for research; this includes the physical and physiological data collected within the Polar Team Pro System.

\section{Risks \& Benefits:}

There are no risks greater than those you encounter in everyday life associated with your involvement in this study given that the data being requested to be examined is currently stored or archived data within the Polar Team Pro Monitoring System. There are no direct benefits to you in having your data included for research purposes. However, your information will help to better understand the athlete's physical responses during team practices and games and during scheduled strength and conditioning sessions.

\section{Participation and Confidentiality:}

Participation in this study is entirely voluntary and will not affect your sport program outcomes. You may withdraw from participation at any time without penalty. If you choose not to participate in this study, do not sign/return this form. Your participation or non-participation will have no effect on your standing on your respective sport team at Illinois State University. Additionally, it is important to note that the strength and conditioning coach/staff and your team's sport coach/coaching staff WILL NOT be informed if you do or do not agree to participate in this study. All data used in this research project will be kept confidential.

The data will be presented in aggregate. No individual names or data will be used. The information obtained from this study may be used for a statistical or scientific purpose with your right of privacy upheld.

Your name will not appear in any of the publications or presentations that result from your involvement with this study. All data will be kept in a locked file within the principle investigator's office/computer system.

\section{Questions:}

If you have any questions about the use of data for research purposes, please contact Dr. Dale D. Brown, School of Kinesiology and Recreation, Illinois State University, Normal, IL by 
phone at 309-438-7547 or email at dbrown@ilstu.edu. If you have any questions about research participant's rights and/or a research related injury or adverse effects, please contact the Research Ethics \& Compliance Office at Illinois State University by phone at (309) 438-5527 and/or email at rec@ilstu.edu.

You must be 18 years of age or older to participate in this study.

If you agree to allow your data to be included in the research study described above, please sign and date this form, and return prior to your assessments. 